\title{
ORIGINAL
}

\section{TRABALHO E SUBJETIVIDADE: CARGAS E SOFRIMENTO NA PRÁTICA DA NUTRIÇÃO SOCIAL}

\author{
WORK AND SUBJECTIVIT: THE DISTRESS AND THE \\ SUFFERING IN THE PRACTICE OF SOCIAL NUTRITION
}

Maria Lúcia Magalhães BOSI'

RESUMO

Este estudo tem como objeto a análise da prática de um segmento específico de trabalhadores sociais do Setor Saúde - os nutricionistas sociais - a partir do referencial teórico relativo às relações saúde/ trabalho. Através de um estudo de caso exploratório, orientado por metodologia qualitativa de pesquisa social, analisaram-se diversos aspectos da subjetividade do grupo concernentes ao cotidiano do seu trabalho no Setor e, em particular, às cargas e sofrimento aí presentes. Os resultados apontam um predomínio de cargas mentais e psico-afetivas sobre as cargas físicas, ao mesmo tempo em que destacam alguns determinantes do quadro identificado. Em contrapartida, indicam um nível elevado de satisfação no trabalho, aspecto que, no plano da subjetividade, se sobrepõe ao sofrimento vivenciado pelo grupo na sua prática profissional.

Termos de indexação: nutricionistas, saúde pública, nutrição, ocupações em saúde.

\begin{abstract}
This study has the purpose of analyzing the praxis of a specific professional segment of social workers of the health care area, that is, the social nutritionists, presenting a theoretical framework concerning the relationship between health and work. Through an investigative case study, guided by the qualitative methodology of social research, a wide range of aspects related to the subjectivity of the group is analyzed. These aspects are concerned with the routine of their work in the sector and, more particularly, with the distress and suffering present there.The results indicate a prevalence of psychoaffective and mental distress over the physical distress, at the same time that points out some determining factors of this identified context. On the other hand, a high level of work satisfaction is found. This aspect, in itself, shades down the suffering experienced by the studied group in their professional praxis.
\end{abstract}

Index terms: nutritionists, public health, nutrition, health occupations.

\section{INTRODUÇÃO}

Este artigo tem como objeto central a análise das repercussões das relações estabelecidas no cotidiano de trabalho sobre a saúde de um segmento específico de trabalhadores sociais do Setor Saúde, os nutricionistas sociais que atuam no campo da Saúde Coletiva.

Inicialmente, procuramos desenvolver uma reflexão eminentemente teórica, de modo a delinear o arcabouço conceitual que fundamenta a nossa

\footnotetext{
(1) Departamento de Saúde Comunitária, Faculdade de Medicina, Universidade Federal do Rio de Janeiro. Av. Trompovski, s/n Bloco K, Ilha do Fundão, 21944-970 - Rio de Janeiro, R. J. Brasil.E-mail: malubosi@uol.com.br
} 
investigação. Nesse sentido, a discussão percorre alguns conceitos centrais para a análise empreendida, dentre eles: "trabalho", "ocupação", "processo de trabalho" e "carga de trabalho".

No âmbito deste estudo, a categoria "trabalho" é situada enquanto um objeto pluridimensional e, portanto, interdisciplinar, focalizando-se as definições mais correntes relacionadas ao termo/conceito, no sentido de distingui-lo de outros conceitos que dele se aproximam.

Recorremos à reflexão filosófica com o objetivo de apontar algumas dimensões que, embora ausentes nas definições apresentadas, redefinem a essência do termo "trabalho" para a existência humana.

Partindo do pressuposto de que a polissemia de um conceito expressa um processo que não se desenvolve no abstrato mas exprime a realidade concreta, buscamos contextualizá-lo historicamente, de modo a assinalar os significados do trabalho humano ao longo da história, ressaltando o novo sentido a ele atribuído na modernidade e, mais precisamente, com o advento da revolução industrial, a partir do modo de produção que, então, se instaura.

Abordamos, também, as relações entre trabalho e saúde, destacando alguns conceitos emergentes neste campo de conhecimento, tais como: "ocupação e profissão". A partir deste quadro teórico, desenvolvemos a análise do material empírico obtido através de estudo de caso conduzido por metodologia qualitativa, através do qual procuramos analisar aspectos distintos da subjetividade dos nutricionistas sociais concernentes ao cotidiano do seu trabalho no campo da Saúde Coletiva e às cargas e sofrimento nele presentes.

\section{CONTEXTO TEÓRICO}

O termo "trabalho" situa-se na interface de várias disciplinas da ciência moderna (Biologia, Física, Medicina, Sociologia, Filosofia, Psicologia, dentre outras) que vão conceituá-lo a partir de recortes diversos, colocando em relevo aspectos específicos para tomá-lo como objeto. A maior parte das definições relaciona-se à sua finalidade, à exterioridade do fenômeno - fim, modo de realização ou efeitos - e não à sua essência, seu significado essencial para o homem:

"Trabalho 1. Aplicação das forças e faculdades humanas para alcançar determinado fim. 2. Atividade coordenada de caráter físico e/ou intelectual necessária à realização de qualquer tarefa, serviço ou empreendimento. 3. 0 exercício desta atividade como ocupação, ofício, profissão. 4. Qualquer obra realizada... 6. Esforço incomum, responsabilidade.... 9. Tarefa, obrigação, responsabilidade..." (Ferreira, 1975).

"O trabalho humano consiste em criar utilidade (...)" (Bergson, 1948).
"O termo trabalho tem significado geral - trabalho ou esforço freqüentemente no sentido de lida penosa ou pesada - do qual derivam várias aplicações e usos análogos (como, por exemplo, trabalhoso: o que custa muito esforço e exige muita persistência em vez de habilidade)" (Fundação..., 1987).

Etimologicamente, "a palavra trabalho exprime mal-estar e significa um instrumento de tortura" (Pina Prata, 1962). Assim é que encontramos várias definições, na verdade, nuances conceituais - cujos significados subjacentes relacionam-se, em geral, à idéia de sacrifício, tarefa penosa, dispêndio de energia.

Entretanto, apesar desta fisionomia que o trabalho humano adquiriu historicamente, ele não é para o homem, em sua essência, um dever inevitável, uma contrariedade; na verdade ele pode mesmo representar o que de mais humano existe no homem: sua criatividade, a expressão de sua marca essencial - a subjetividade - representando um fator essencial ao equilíbrio e desenvolvimento humano (Dejours et al., 1993).

No que se refere à palavra "ocupação", seu emprego segue o uso comum dado a este termo, significando emprego ou negócio, confundindo-se em alguns casos, com trabalho e profissão:

"A ocupação de uma pessoa é a espécie de trabalho por ela desenvolvido, independentemente da indústria em que esse trabalho é realizado e do status do indivíduo" (International Labour..., 1949).

Já o termo "profissão" vai designar aquelas ocupações que tendo assumido uma posição privilegiada na divisão do trabalho, detêm o controle sobre "a determinação da essência do seu próprio trabalho". Neste sentido, aponta-se a autonomia como a variável estratégica numa diferenciação entre "profissão" e "ocupação" (Friedson, 1978). Em seu uso mais geral, o conceito profissão refere-se àquelas ocupações que para seu exercício exigem habilitação especializada obtida em cursos ou treinamentos formais, oferecidos por instituições legitimadas.

Em síntese, poderíamos dizer que profissão é um tipo especial de ocupação, uma posição na divisão do trabalho, da qual se obtém os meios de sobrevivência.

Se, por um lado, as definições até aqui apresentadas conseguem, de algum modo, auxiliar a diferenciação semântica entre esses termos elevando-os à categoria de conceitos, por outro, não conseguem dar conta do significado constitutivo das diferentes modalidades de trabalho na vida humana. Para tal, faz-se necessário transpor essa primeira apreensão, buscando outros significados.

\section{Ampliando o conceito}

Ao iniciarmos esta reflexão, lembramo-nos de uma passagem na obra "Meditação da Técnica" onde o filósofo Ortega y Gasset afirma serem de uma 'pavorosa superficialidade' as respostas que se dão a quase todas as 
questões que se referem ao humano no homem. E, prossegue ele:

\begin{abstract}
“...não será possível por alguma clareza nelas se não nos resolvermos a tomá-las no estrato profundo onde surge todo o propriamente humano. Enquanto prosseguimos a falar de assuntos que nos dizem respeito, dando por suposto que sabemos bem o que é humano, somente conseguiremos deixar sempre de lado a verdadeira questão" (Ortega y Gasset, 1963).
\end{abstract}

Embora Ortega se referisse às respostas dadas à questão - o que é a técnica? - não pudemos deixar de estender suas reflexões a algumas indagações centrais na análise aqui empreendida: o que é trabalho? O que, em essência, escapa às definições comumente encontradas? Que importância tem o trabalho na vida humana?

Tomando como base algumas obras deste filósofo, procuramos resgatar o sentido de trabalho, ocupação e profissão na vida humana, encontrando, ao final, uma redefinição que acabou por situar estes termos em dimensões bastante distintas das que inicialmente nos orientavam.

A idéia de "vida" é o ponto de partida da meditação orteguiana. Para o autor, a vida não é algo abstrato; ao contrário, viver é estar em contato com as coisas, é ocupar-se. Também a idéia de ocupação é fundamental para a perspectiva com que Ortega vai definir a vida, na medida em que para viver temos, inevitavelmente, que fazer algo já que a vida não nos é dada pronta:

"O modo de ser da vida nem sequer como simples existência é ser já, posto que o único que nos é dado e que há quando há vida humana é ter que fazê-la, cada um a sua. A vida é um gerúndio e não um particípio: um faciendum e não um factum" (Ortega y Gasset, 1935).

Nessa perspectiva filosófica, trabalho e ocupação são termos usados para expressar uma dimensão fundamental da vida, "um constituinte vital"; não apenas "dispêndio de esforço" ou "realização de tarefas" mas o elemento básico da vida humana. O trabalho não é, portanto, como há pouco referimos, apenas uma contrariedade ou uma imposição para o homem, mas é o que lhe permite realizar-se, criar-se a si mesmo em todas as suas dimensões. Na medida em que molda a natureza que lhe é exterior, o homem molda a si mesmo (Fromm, 1944).

Mas sendo a vida uma constante tensão entre o "eu" - o projeto que somos - e nossas circunstâncias concretas, o homem, como nos lembra Ortega, encontra-se frente à difícil tarefa de se realizar através das suas atividades.

É interessante observar que os antigos dividiam a vida em duas zonas: otium (ócio) e nec-otium. O otium não correspondia à negação do fazer mas à ocupação voltada para a realização do humano no homem (aí se situava, por exemplo, a arte). O nec-otium significava a zona do esforço para a satisfação das necessidades elementares com as quais o humano no homem não se identifica (Ortega y Gasset, 1963).
O nec-otium corresponde, portanto, ao caráter negativo que a ocupação tem para o homem e, para a maioria, parece ser esta a face que restou do trabalho em seu sentido original. Infelizmente, apesar da diversidade de opções profissionais que hoje nos são oferecidas e ao contrário do que ocorria com os antigos ofícios, é cada vez mais rara a coincidência entre a vocação e a profissão do indivíduo na medida em que esta é ditada por interesses alheios aos "interesses fundamentais da vida".

A partir dessas idéias, podemos apreender o sentido essencial que o trabalho tem para a existência humana. $\mathrm{O}$ trabalho, quando não oprime e aliena, ou seja, quando realiza o desejo e as potencialidades do trabalhador, constitui uma dimensão de interioridade da vida; é um dos caminhos que levam o homem à sua plena realização, à sua felicidade. Mas a luta pela reprodução material impõe ao homem, muitas vezes, a execução de tarefas alheias ao seu desejo às quais ele jamais se habitua. Em decorrência, conforme ressalta Ortega y Gasset, o termo "ocupação" se reveste de um sentido freqüentemente pejorativo, significando um afastamento da vida efetivamente aspirada, condição que aceitamos para depois buscarmos a realização das nossas potencialidades (Ortega y Gasset, 1963).

Contudo, a alienação dos homens no processo de trabalho, em todas as suas formas, "não é uma conseqüência necessária da condição humana mas um desequilíbrio, fruto da configuração que tem tomado historicamente as forças produtivas e as relações sociais de produção" (Neffa, 1988). Cabe, portanto, uma reflexão sobre esta "configuração histórica" que veio a caracterizar o trabalho como uma verdadeira tortura, a própria destruição do homem, ao invés de contribuir para a realização das suas potencialidades.

O processo de trabalho, processo pelo qual o homem molda a natureza que lhe é exterior pode ser definido, em sua dimensão técnica, como o processo pelo qual um dado objeto é transformado num produto com valor de uso, ou seja, que visa a satisfação de necessidades humanas experimentadas pelo conjunto da população.

Dá-se, portanto, a articulação de três componentes fundamentais: a atividade humana orientada para um fim; os meios de trabalho e os objetos de trabalho (Marx, 1988).

Mas se, por um lado, o processo de trabalho pode ser decomposto em seus elementos simples, sendo entendido como um processo de transformação, esta transformação não se dá abstratamente mas dentro de certas relações sociais que se estabelecem no curso do referido processo. São essas relações que definirão as condições de trabalho, a distribuição do produto bem como a configuração geral das classes e a divisão do trabalho entre diferentes atividades.

O processo de trabalho é, portanto, um conceito que se refere não só à base técnica mas à organização social do trabalho. É processo técnico, social e econômico (Gonçalves, 1986; Marx, 1988; Laurell, 1989). 
Para a apreensão do processo de trabalho em sua dimensão histórica, ou seja, o modo pelo qual se dá concretamente a produção humana, é mister considerar a relação entre o sistema produtivo e o movimento do capital com a ascensão de formas específicas de divisão do trabalho (Codo et al., 1993). Deste modo podemos compreender a "imensa distância histórica" a que Marx já se referia em sua alusão à condição instintiva, natural, do trabalho primitivo se comparado às características negativas e fragmentadoras do trabalho quando este se transforma numa mercadoria.

Aí reside a gênese da transmutação do trabalho como dimensão fundamental da vida em "instrumento de tortura" que é o novo sentido a ele conferido com o advento do modo de produção capitalista (Ortega y Gasset, 1963; Brighton, 1976; Porto, 1987.

Não é nossa intenção, no espaço desta reflexão, discorrer sobre as diferentes feições com as quais o processo de trabalho se apresentou e vem se apresentando; entretanto, parece-nos útil para a compreensão desta mudança essencial no significado do trabalho humano relembrar o fato de que ele (o trabalho) adotou diversas modalidades ao longo da história, modalidades estas decorrentes, como já dissemos, do sistema produtivo e do movimento do capital. Em função deste desenvolvimento, diferentes graus e tipos de divisão social e técnica do trabalho vão surgindo, acarretando inúmeras conseqüências na vida dos trabalhadores (Porto, 1987).

De elemento de equilíbrio, o trabalho passa a representar um risco à vida, passando esta problemática a configurar um novo campo de estudo, o das relações entre Saúde e Trabalho, ressaltando alguns conceitos centrais para a compreensão dos efeitos e da importância do trabalho na totalidade da existência humana - objetiva e subjetiva - na sociedade contemporânea.

\section{Saúde e Trabalho}

Nem sempre Saúde e Trabalho foram entendidos como fenômenos interligados. Conforme destacam Dejours et al. (1993):

"Os especialistas e os cientistas levaram muito tempo para compreender que o trabalho é um dado fundamental da Saúde".

Entretanto, há algum tempo essa inter-relação já se encontra estabelecida, reconhecendo-se não somente a influência negativa como o valor positivo que o trabalho possui para a saúde e o equilíbrio do homem (Marchewski, 1982; Garfield, 1983; Duarte, 1986; Chanlat, 1990; Dejours \& Adboucheli, 1990; Dejours \& Burlot, 1990; Dejours et al., 1993; Seligman-Silva, 1994).

No campo de estudo das relações entre Saúde e Trabalho, o conceito de carga de trabalho, que teve sua origem principalmente na ergonomia francesa, foi ganhando relevo (Brito \& Porto, 1991). Carga de trabalho é um conceito que busca dar conta da complexa e dinâmica relação entre o trabalhador e seu trabalho o que, em última análise, vai influenciar ou mesmo determinar seu estado de saúde.

O conceito de carga de trabalho representa um avanço na análise da relação Trabalho e Saúde, na medida em que incorpora não só a dimensão biológica (física) do homem mas outras esferas envolvidas no trabalho, tais como, a mental e a psico-afetiva. Desta forma, para toda atividade se apresenta uma certa carga de trabalho, na qual três componentes interrelacionados estão presentes, afetando-se reciprocamente: a carga física - resultado da interação entre o corpo físico do trabalhador em atividade, e o ambiente de trabalho; a carga mental/cognitiva - resultante dos processos cognitivos envolvidos nas atividades de trabalho, qualquer que seja a sua natureza; e a carga psíquica - aspecto analisado pela chamada "psicopatologia do trabalho" e que diz respeito aos "componentes afetivos negativos desencadeados ou agravados pelo processo de trabalho". O medo e a ansiedade são exemplos deste componente (Brito \& Porto, 1991).

É interessante notar, como destaca Dejours, que:

"... se a relação corpo-condição de trabalho muitas vezes é estudada corretamente, ao contrário, nunca se faz menção às repercussões do perigo real no nível mental, da carga de trabalho psíquica inerente ao trabalho... que, entretanto, faz parte do desgaste do organismo" (Dejours, 1987).

Vale ressaltar que se a inclusão de novas dimensões vem ampliando o conceito de carga, este não está destituído de certas limitações, a começar pela própria dificuldade de se apreender a globalidade da carga a que está submetido cada trabalhador, sobretudo se considerarmos as cargas psíquicas. Além disso, "o próprio termo carga permite apreender apenas o aspecto negativo do trabalho" (Dejours et al., 1993). Como expressar o aspecto positivo?

Na tentativa de superar esta limitação começam a surgir alguns modelos que, afastando-se da pretensão de mensuração objetiva, avançam no sentido de tentar caracterizar o componente psíquico do trabalho realizado atentando para o fato de que "em se tratando da carga psíquica, o perigo principal é o da subutilização ou da repressão das aptidões psíquicas, fantasiosas ou psicomotoras, que ocasionam uma retenção de energia" (Dejours et al., 1993).

Resulta daí que o bem-estar psíquico não é fruto da inércia ou da ausência de atividade, mas do engajamento numa tarefa gratificante onde as energias possam dispor de um livre funcionamento, o que remete à valorização das condições e das modalidades a partir das quais o trabalho se organiza.

Dejours afirma que a saúde do corpo é função das condições de trabalho, enquanto que o sofrimento mental resulta da organização do trabalho, embora, evidentemente, não sejam componentes isolados. Por condição de trabalho entende-se: o ambiente físico, 
químico e biológico, as condições de higiene e segurança, as características antropométricas do posto de trabalho. Já a organização do trabalho refere-se à divisão do trabalho, ao conteúdo da tarefa, ao sistema hierárquico, às modalidades de comando e às relações de poder, às questões ligadas à responsabilidade, etc. Relações de trabalho seriam, portanto, "todos os laços humanos criados pela organização do trabalho: relação com a hierarquia, com as chefias, com a supervisão, com outros trabalhadores..." (Dejours, 1987).

Neffa (1988) utiliza o conceito Condiciones y Medio Ambiente de Trabajo (CYMAT) no qual as condições de trabalho referem-se aos aspectos organizacionais acima citados, correspondendo ao que Dejours concebe como organização do trabalho.

Segundo esses autores, os problemas que se apresentam na esfera do trabalho expressam o "conflito que opõe o desejo do trabalhador à realidade do trabalho, colocando face a face seu projeto espontâneo e a organização do trabalho que limita a realização desse projeto e prescreve um modo operatório preciso" (Dejours et al., 1993).

A partir desse arcabouço teórico, interessou-nos neste estudo contribuir para análise da prática profissional dos trabalhadores sociais na Saúde, aqueles que atuam no campo da Saúde Pública/Saúde Coletiva, a partir de um estudo de caso junto aos nutricionistas sociais (nutricionistas com formação e atuação específicas nessa área). Procuramos investigar sua inserção no processo de trabalho, particularmente no que se refere às relações entre a prática profissional e à organização social do processo, conferindo destaque à subjetividade e, em particular, ao sofrimento oriundo das condições de trabalho tal como percebidas por este grupo específico de trabalhadores.

\section{CASUÍSTICA E MÉTODOS}

Optamos por uma abordagem que privilegiasse a subjetividade dos profissionais a respeito da sua prática; o material trabalhado foi, portanto, o discurso do grupo sobre os aspectos focalizados.

As concepções de um grupo sobre um dado fenômeno decorrem, em última instância, da sua inserção na estrutura social com implicações na esfera cultural e cognitiva, apreensíveis em seu universo simbólico (Thiollent, 1980). A complexidade dessa determinação impõe a necessidade de se considerar o material subjetivo enquanto expressão primeira, respeitando-se a singularidade e a heterogeneidade que se expressa nas narrativas (Amatuzzi, 1989)

Assim, para o estudo em questão, optou-se pelo uso de procedimentos não-diretivos, elegendo-se como técnicas entrevistas associadas a grupos-focais, que possibilitaram a emergência de um discurso fundado na lógica do grupo, alcançando conteúdos menos superficiais que dificilmente se apresentariam com o emprego de procedimentos diretivos (Kandel, 1972; Creswell, 1994).

Finalmente, com relação à amostra na medida em que se trata de um estudo eminentemente qualitativo não se colocou para nós questões como "representatividade" ou "generalização" nos termos em que estes aspectos são considerados pela tradição quantitativa (Minayo, 1992). Adotamos como critério de suficiência a reiteração (recorrência) das categorias empíricas no material discursivo, sinalizando-nos a recuperação do modelo focalizado nesta investigação.

Para tanto, foram realizadas 20 entrevistas em profundidade associadas a 2 grupos focais nos quais participaram outros 20 profissionais. A investigação orientou-se apenas por um eixo (sem adoção de um roteiro pré-estruturado) a partir do qual a "conversa" percorreu questões diversas relacionadas ao trabalho do grupo, tais como: sua organização social, atividades rotineiras, concepção acerca do conteúdo do trabalho desenvolvido, sofrimento e prazer no exercício profissional, aspirações, etc.

A categoria ocupacional eleita neste estudo representa um segmento quase que exclusivamente feminino, segundo os dados disponíveis que indicam ser a quase totalidade da profissão constituída por mulheres (99\%), característica que se associa a diversos elementos presentes na própria história do surgimento deste grupo profissional (Bosi, 1996).

De acordo com o critério de seleção adotado, todos os entrevistados se enquadravam em termos do perfil de formação e prática no que aqui se concebe como "nutricionistas sociais", profissionais que concluíram formação em cursos de pós-graduação na área de Saúde Pública e nela atuavam desenvolvendo suas atividades na cidade do Rio de Janeiro. No que se refere às principais atividades desenvolvidas por este segmento, destacam-se: atendimento nutricional; educação nutricional; atividades de treinamento de pessoal auxiliar; elaboração de estatísticas/informes técnicos e diagnóstico nutricional, desenvolvendo uma parcela significativa do seu trabalho junto às comunidades, em áreas periféricas.

Se, por um lado, as atividades citadas predominam no cotidiano de trabalho dos nutricionistas sociais, por outro, não esgotam o papel potencial a ser desempenhado em equipes interdisciplinares, sobretudo naquelas voltadas à formulação de políticas públicas no Setor. Contudo, conforme apontado por diferentes autores, a prática massiva não ultrapassa o nível de execução de ações já programadas e normatizadas, sem a participação efetiva da categoria na discussão dos objetivos e no planejamento das intervenções (Bosi, 1988; Prado \& Abreu, 1991; Bosi, 1996).

Cabe assinalar um fato importante e já apontado na literatura (Bosi, 1996), que é a importância de se considerar 
os nutricionistas sociais como um grupo em si heterogêneo, no qual embora apareçam alguns elementos comuns que o diferenciam dos demais grupos externos à área, também apresentam diferentes concepções do social, em parte, ligadas à própria evolução histórica dos conceitos neste campo de discurso e prática.

\section{RESULTADOS}

A análise dos depoimentos das profissionais entrevistadas aponta um predomínio das cargas cognitivo-mentais e psico-afetivas sobre as cargas físicas no cotidiano do seu trabalho. Embora evidentemente repercutam no plano corporal, as queixas físicas não aparecem nos discursos emitidos.

Uma importante carga psíquica que aparece nos relatos é o medo; mas um medo que difere daquele que se apresenta no cotidiano do operariado conforme apontado por estudos como o de Weil (1979). No que se refere aos nutricionistas sociais, não se trata de uma dinâmica de auto-repressão (Seligman-Silva,1994), mas um dado que aparece relacionado com outros determinantes, dentre eles, o crescimento da violência e do "poder jurisdicional do crime organizado" (Duarte et al., 1992).

Sendo a prática da Nutrição Social composta por atividades que, muitas vezes, se desenvolvem em periferias, no caso deste estudo, em favelas, numa área (Rio de Janeiro, RJ) onde a violência atinge níveis alarmantes, há riscos muito concretos. Os profissionais que há anos vêm desenvolvendo atividades nestes locais, sentem de perto o crescimento assustador do problema da violência urbana:

"A questão da violência... hoje ela é concreta demais. Não há mais certos valores éticos na favela... sinto uma tensão que não sentia antes, quando vou a uma favela" (Entrevista n.3).

"O crescimento do narcotráfico e sua forte influência no dia-a-dia da população favelada não mais garantem os antigos vínculos. Por outro lado, o controle das Associações de Moradores por estes grupos dificultam enormemente o trabalho com a população" (Entrevista n.4).

São novos desafios impostos pelo dinamismo e historicidade da prática na área social. Da mesma forma, as cargas psíquicas, expressas no sentimento de ansiedade e de insatisfação/frustração parecem muito presentes. Pelos relatos, pudemos perceber que estes sentimentos decorrem basicamente de uma vivência de descontinuidade do trabalho e da própria natureza dos problemas desta área, que não são apenas "problemas técnicos", já que o grupo não percebe a Nutrição como um fenômeno estritamente biológico mas sócio-histórico.

Bosi (1996) estudando a identidade e a profissionalização dos nutricionistas, identifica junto ao segmento dos nutricionistas sociais uma concepção de Nutrição que articula o ato fisiológico da alimentação com distintos aspectos da organização social, reconhecendo na alimentação não só sua dimensão biológica mas seu caráter social, de necessidade, ligada a aspectos econômicos e à dimensão simbólica. Isto faz com que o grupo remeta sua prática para esferas mais abrangentes, onde o papel do profissional perde força:

“... a Nutrição Social remete a muitas impossibilidades que paralisam a ação. Há limites que são estruturais. E eu quero que algo mude..." (Entrevista n.2).

É importante ressaltar que os elementos que aqui configuram cargas cognitivo-mentais e, sobretudo, psico-afetivas não são exclusivos do cotidiano de trabalho da categoria em questão. Ao contrário, pensamos que muitos deles são vivenciados por outros segmentos sociais ou mesmo por qualquer cidadão que hoje se defronta com desafio de reproduzir sua existência ante os problemas sociais e às disparidades existentes na nossa sociedade, em especial, no espaço das grandes cidades.

De qualquer forma, a intensidade destas cargas parece-nos particularmente importante quando estas se configuram como um traço que se expressa de forma contínua no cotidiano de trabalho de um grupo. Parece ser este o caso do segmento aqui focalizado.

Quanto às demais categorias que exercem sua prática em circunstâncias análogas, podemos hipotetizar algumas aproximações, embora se façam necessários estudos específicos de modo a confirmar essa suposição.

A dificuldade de obter resultados imediatos e a percepção do agravamento da problemática nutricional/ alimentar no país frente à qual sua ação é percebida como insignificante são fontes de uma grande ansiedade e desânimo para o grupo.

Em parte, esse movimento percebido, muitas vezes, como "crise", se deve à concepção de Nutrição do grupo, cuja amplitude (e interdisciplinaridade) engloba muitos domínios que não mais podem ser monopólio de uma única categoria profissional, circunstância que se expressa como carga mental e psíquica. Apesar disto, o grupo resiste, atitude que se traduz num "repensar" contínuo da sua prática.

A própria complexidade do objeto (Nutrição), particularmente no que se refere à dimensão social, coloca os nutricionistas que atuam nesta área frente a impasses cuja solução concreta remete a reflexões teóricas bastante distantes da formação recebida nos cursos de graduação cujo enfoque, predominantemente biológico, conforme apontado em outros estudos (Bosi, 1988; Ypiranga \& Gil, 1989; Bosi, 1994), não instrumentaliza o profissional para as exigências de uma prática que transcende os limites dos problemas que pedem soluções técnicas, ou seja, voltadas para os efeitos.

Este aspecto, a resistência do grupo como alternativa à desistência, conforme apontamos, acaba por se traduzir em cargas cognitivo/mentais e psíquicas. As primeiras, devido ao grande investimento que o grupo precisa realizar 
na busca de uma qualificação que sua formação não garante, uma vez que a base cognitiva da profissão é percebida como um obstáculo importante, tanto para a conquista de autonomia técnica quanto para a construção de uma prática coerente com a situação nutricional prevalecente no país:

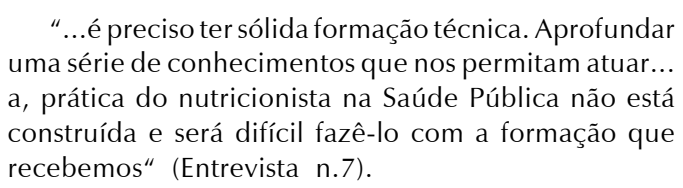

Esse esforço, por seu turno, se traduz numa forte ansiedade, dada a dificuldade que esses profissionais enfrentarão para lidar com um referencial teórico absolutamente distinto daquele que lhes orientava anteriormente:

"Sinto que não sei nada... é muito difícil a iniciação no código das Ciências Sociais" (Entrevista n.9).

"Na adaptação do conteúdo da tarefa às competências reais do trabalhador, o sujeito pode encontrar-se em situação de subemprego de suas capacidades ou, ao contrário, em situação muito complexa correndo assim o risco de um fracasso" (Dejours, 1987).

Parece-nos que ambas cargas estão presentes na trajetória dos nutricionistas sociais. Fugindo da desqualificação imposta pelo trabalho nas áreas clínica e de produção (BOSI, 1996), vão se deparar com o sentimento de incompetência para o trabalho na Área Social. Ainda assim, este último sofrimento parece mais suportável pois:

"Executar uma tarefa sem investimento material ou afetivo exige a produção de esforço e de vontade, em outras circunstâncias suportada pelo jogo da motivação e do desejo" (Dejours, 1987).

A impossibilidade de criar e a falta de autonomia no cotidiano de trabalho são algumas das caraterísticas que, segundo nosso estudo, este segmento não consegue suportar. Isto nos faz retomar a noção de projeto presente no pensamento Orteguiano já que os nutricionistas sociais, segundo cremos, buscam a coincidência entre a interioridade e a profissão, procurando situar seu trabalho na zona do otium - a ocupação dirigida para a realização do humano no homem.

Nesse contexto, um aspecto importante parece ser a organização social do trabalho neste campo de prática que, conforme já assinalado, permite a autonomia e a criatividade, possibilitando a manutenção de certas características que remetem ao trabalho artesanal, sendo muito valiosas para a realização humana:

"Em termos de economia psíquica, esta adaptação espontânea do trabalho ao homem corresponde à procura, à descoberta, ao emprego e à experimentação entre os desejos e a realidade. Em tais condições, podemos perceber um movimento consciente de luta contra a insatisfação ou contra a indignidade, a inutilidade, a desqualificação e a depressão graças aos privilégios de uma organização deixada, em grande parte, à discrição do trabalhador... Mesmo as más condições de trabalho são, no conjunto, menos temíveis do que uma organização do trabalho rígida e imutável" (Dejours, 1987).

Quanto à organização social da prática, cabe ressaltar que a Nutrição Social se apresenta como um campo onde é grande a criatividade e autonomia. Isso se deve, em parte, ao próprio locus desta prática que, ao contrário das demais, não se realiza no espaço das empresas ou dos hospitais de grande porte. Prado (1993), num estudo desenvolvido junto a nutricionistas atuantes em Centros Municipais de Saúde (RJ), constatou que, neste espaço, a criatividade e a autonomia não ficam impedidas.

No mesmo sentido, Bosi (1996) aponta a Saúde Pública como uma "terceira alternativa... na esperança de construção de uma prática mais ampla ou de fuga à rigidez da organização do trabalho". Ao que parece, na Saúde Pública, há um espaço menos restrito se comparada a outros locais de prática:

"Como profissional nutricionista atuando na área social, eu não consigo encontrar uma só tarefa rotineira. É isto o que me fascina ... o dinamismo do trabalho" (Entrevista n.11).

Quanto à hierarquia, apresenta-se pouco marcada, pouco rígida, embora as equipes, algumas vezes constituídas somente por nutricionistas, variem bastante em termos de relações. Segundo os discursos analisados, os principais conflitos "são de natureza ideológica", expressão que se refere à influência partidária na condução dos trabalhos (sociais), levando a divergências entre membros filiados a diferentes correntes teóricas ou partidárias.

Em nenhum momento das falas aparecem referências a questões ligadas à divisão técnica no interior do trabalho em saúde; ao contrário do que ocorre em outros espaços, as relações com as outras corporações não se mostram problemáticas para o grupo, o que, em parte, pode ser atribuído à readjetivação que o rótulo "sanitarista" parece promover, com impactos significativos na identidade dos profissionais que percorrem esta formação. Noutras palavras, a condição de "sanitarista" parece sobrepor-se à formação de origem (nutrição, medicina, enfermagem, farmácia, etc.) diluindo - no plano objetivo e subjetivo - a hierarquia para profissional observada em outros espaços, notadamente, no espaço hospitalar.

No contato estabelecido durante este estudo com esses profissionais, pudemos perceber o quanto a questão da autonomia e a criatividade, bem como a perspectiva de um trabalho que os "realize", "que faça sentido", Ihes é fundamental, na medida em que, conforme já assinalado, possibilitam a manutenção de certas características que remetem ao trabalho artesanal.

Talvez por isso, apesar de tudo, o grupo numa relação descontentamento/realização tenda para o segundo sentimento. Tal como figura no pensamento Orteguiano, a decisão é essencial às suas vidas. Evidentemente, uma decisão, em geral, implica um certo custo. E se esta decisão aponta para um crescimento, em geral não se faz sem angústia, sem sofrimento. 
“... é drama porque não se faz sem interrogação e angústia. A faceta dramática da vida provém, assim, de sua própria estrutura. Se o homem fosse um ser estático; se a vida humana, em vez de ocupação, e preocupação, fosse crescimento espontâneo 'natural', encontrar-se-ia liberta de problemas e de perplexidade" (Pina Prata, 1962).

Os Nutricionistas Sociais parecem acreditar nisso até porque, sentem no seu íntimo que:

“Quem se lança na nutrição social já tem uma inquietação interior que o faz se sentir diferente. O investimento emocional (na vida) é muito grande. É difícil, depois, fechar os olhos" (Entrevista n. 14).

\section{CONSIDERAÇÕES FINAIS}

Ao longo desta investigação, pudemos aprofundar nossa reflexão acerca da importância do trabalho como espaço vivencial fundamental para a realização humana. Também assinalamos a interface existente entre trabalho e saúde, temática já bastante reconhecida, em especial, no campo da Saúde Coletiva, cuja amplitude e historicidade lança novos e importantes desafios.

Tal como procuramos demonstrar, a categoria trabalho engloba múltiplas e distintas dimensões, por vezes, contraditórias, exigindo para sua compreensão um olhar interdisciplinar que busque restituir ao fenômeno sua complexidade. Para tanto, há que se considerar não apenas suas expressões visíveis, sua "morfologia", mas entendê-lo como fazendo parte do humano, portanto daquilo que não pode ser descrito mas compreendido. Deste modo, faz apelo à incorporação dos sujeitos, de suas vivências, tal como por eles percebidas e descritas.

No âmbito desta investigação, procuramos contribuir com essa vertente, buscando conhecer mais de perto diferentes aspectos da subjetividade dos nutricionistas sociais - categoria que motivou este estudo concernentes ao seu cotidiano de trabalho, conferindo destaque às cargas a que se vêem submetidos. Os resultados indicam a presença de importantes cargas, com o predomínio das mentais e psico-afetivas sobre as físicas. Dentre as primeiras, destacam-se o medo, a ansiedade, o sentimento de desânimo e de impotência; cargas relacionadas por um lado, à problemática sobre a qual atuam e, por outro à formação profissional da categoria, percebida como insuficiente para uma atuação mais eficaz.

Em contrapartida, os dados apontam um nível elevado de satisfação no trabalho decorrente, sobretudo, da organização pouco rígida nesse locus de prática, aspecto que possibilita a manutenção de certas características consideradas pelo grupo como fundamentais para a sua realização tais como a autonomia e a criatividade. Este aspecto faz com que o prazer e a satisfação se sobreponha ao sofrimento vivenciado no trabalho.

\section{REFERÊNCIAS BIBLIOGRÁFICAS}

AMATUZZI, M.M. O Resgate da fala autêntica. Campinas : Papirus, 1989. 200p.

BERGSON, H. L'Évolution créatrice. Paris : PUF, 1948. p.297.

BOSI, M.L.M. A face oculta da nutrição: ciência e ideologia. Rio de Janeiro : Espaço e Tempo, 1988. 220p.

BOSI, M.L.M. A nutrição na concepção científica moderna: em busca de um novo paradigma. Revista de Nutrição da Puccamp, Campinas, v.7, n.1, p.32-47, 1994.

BOSI, M.L.M. Profissionalização e conhecimento: a nutrição em questão. São Paulo : Hucitec, 1996. 205p. p.131.

BRIGHTON LABOUR PROCESS GROUP. O processo de trabalho capitalista. Capital and Class, 1. London, 1976. (Mimeografado).

BRITO, J.C., PORTO, M.F.S. Processo de trabalho, riscos e cargos à Saúde. Rio de Janeiro, 1991. p.14. Monografia (Especialização em Saúde do Trabalhador) - CESTEH, Escola Nacional de Saúde Pública, Fundação Oswaldo Cruz, 1991. (Mimeografado)

CHANLAT, J.F. Théories du stress et psychopatologie du travail. Prevenir, Marselhas, n.20, p.117-126, 1990.

CODO, W., SAMPAIO, J.J.C., HITOMI, H. Indivíduo, trabalho e sofrimento: uma abordagem interdisciplinar. Petrópolis : Vozes, 1993. 280p.

CRESWELL, J.W. Research design: qualitative and quantitative approaches. California : SAGE Publications, 1994. 228p.

DEJOURS, C. A loucura do trabalho. São Paulo : Oboré Editorial, 1987. p.25,52,66.

DEJOURS, C., ADBOUCHELI, E. Itineraire theorique en psychopatologie du travail. Prevenir, Marselha, n.20, p.127-149, 1990.

DEJOURS, C., BURLOT, A. Contribution de la psychopathologie du travail á l'etude de l'alcoolisme. In: DEJOURS, C., VEIL, C.E WISNER, A. (Org.). Psychopatologie du travail. Paris : Enterprise Moderne d'Edition, 1990. p.105-111.

DEJOURS, C., DESSORS, D., DERIAUX, F. Por um trabalho, fator de equilíbrio. Revista. de Administração de Empresas, São Paulo, v.33, n.3, p.98-104, 1993.

DUARTE, L.F.D. Da vida nervosa nas classes trabalhadoras urbanas. Rio de Janeiro : Jorge Zahar, 1986.

DUARTE, L.F.D., BARSTED, L.L., TAULOIS, M.R., GARCIA, M.H. Vicissitudes e limites da conversão à cidadania nas classes populares. Rio de Janeiro : [s.n.], 1992. (Mimeografado).

FERREIRA, A.B.H. Novo dicionário Aurélio. 5.impr. Rio de Janeiro : Nova Fronteira, 1975. 1499p.

FRIEDSON, E. La professión medica: un estudio de Sociologia del Conócimiento Aplicada. Barcelona : Península, 1978. 373p. (Séries: Homo Sociologicus, 17).

FROMM, E. Psicoanálisis de la Sociedad Contemporánea. México : FCE, 1944. 202p.

FUNDAÇÃO GETúlIO VARGAS. Dicionário de Ciências Sociais. 2.ed. Rio de Janeiro, 1987. p.1247.

GARFIELD, J. O trabalho alienado, stress e doença coronariana. In: NUNES, E. (Org.). Medicina social. São Paulo : Global, 1983. p.158-175: Textos 3. 
GONÇALVES, R.B.M. Tecnologia e organização social das práticas de saúde: características tecnológicas do processo de trabalho na Rede Estadual de Centros de Saúde de São Paulo. São Paulo, 1986. Tese (Doutorado) - Faculdade de Medicina, Universidade de São Paulo, 1986.

INTERNATIONAL LABOUR OFFICE. International Standard Classification of Ocupations Geneve, 1949. p.4.

KANDEL, L. Reflexões sobre o uso da entrevista especialmente a não diretiva, e sobre a pesquisa de opinião. Epistemologie Sociologique, n.13, p.25-26, 1972. (Tradução de Ruth Soffily Dias).

LAURELL, A.C., NORIEGA, M. Processo de produção e saúde: trabalho e desgaste operário. São Paulo : Hucitec, 1989. $331 \mathrm{p}$.

MARX, K. O Capital: Livro 1. Rio de Janeiro : Bertrand Brasil, 1989.

MASCHEWSKI, W. The Relation between stress and myocardial infarection: a general analysis. Social Science and Medicine, Oxford, v.16, p.455-462, 1982.

MINAYO, M.C.S. O desafio do conhecimento: pesquisa qualitativa em saúde. São Paulo: Hucitec, 1992. 269p.

NEFFA, J.C. Que son las condiciones y medio ambiente de trabajoi Propuesta de una nueva perspectiva. Buenos Aires : Unión Obrera Metalúrgica SECYT, 1988. p.23.

ORTEGA y GASSET, J. História como sistema. [s.I. : s.n.], 1935. p.13-107. (O.VI).

ORTEGA y GASSET, J. Meditação da técnica. Rio de Janeiro : Livro Ibero-Americano, 1963. 135p.
PINA PRATA, F.X. Dialética da razão vital. Lisboa : Livraria Morais, 1962.

PORTO, M.F.S. O trabalho aprisionado: reflexões sobre o trabalho repetitivo no capitalismo. Rio de Janeiro, 1987. 236p. Tese (Mestrado) - Universidade Federal do Rio de Janeiro, 1987.

PRADO, S.D. Autonomia tentadora e reificada: estudo sobre nutricionistas do centros municipais de saúde do Rio de Janeiro. Rio de Janeiro, 1993. 145p. Dissertação (Mestrado em Saúde Pública) - Escola Nacional de Saúde Pública, Fundação Oswaldo Cruz, 1993.

PRADO, S.D., ABREU, M.S. Nutricionista: onde trabalha? Quais suas condições de trabalho? Revista de Nutrição da Puccamp, Campinas, v.4, n.1/2, p.65-92, 1991.

SELIGMAN-SILVA, E. Desgaste mental no trabalho dominado. Rio de Janeiro : Cortez, 1994. 324p.

THIOLLENT, M. Critica metodológica, investigação social e enquete operária. São Paulo : Polis, 1980. 270p.

WEIL, S. A condição operária e outros estudos sobre a opressão. Seleção e apresentação. Traduzido por Therezinha G. Langlada. Rio de Janeiro : Paz e Terra, 1979. 400p.

YPIRANGA, L., GIL, M.F. Formação profissional do nutricionista. Por que mudar? In: SEMINÁRIO NACIONAL SOBRE ENSINO DE NUTRIÇÃO, 2., 1989, Goiânia. Anais... Goiânia : FEBRAN, 1989. p.19-36.

Recebido para publicação em 15 de dezembro de 1998 e aceito em 31 de agosto de 1999. 